\title{
A atuação do psicólogo escolar na rede particular de ensino
}

\author{
Cláudia Silva de Souza \\ Maria José Ribeiro \\ Silvia Maria Cintra da Silva
}

\begin{abstract}
Resumo
Os trabalhos encontrados na literatura recente acerca da atuação do psicólogo escolar focam, predominantemente, o âmbito do ensino público. Assim, este estudo investiga a prática deste profissional na rede particular de ensino, fundamentado em pressupostos qualitativos, sob a perspectiva histórico-cultural. Realizamos entrevistas semiestruturadas com doze psicólogos escolares da rede particular de ensino da cidade de Uberlândia/MG e constatamos que a inserção destes no segmento educacional privado reflete, dentre outros fatores, questões históricas relacionadas à constituição da Psicologia Escolar no Brasil, desdobradas na imagem social do psicólogo escolar. As modalidades de trabalho desenvolvidas pelos participantes deste estudo são predominantemente tradicionais, sustentadas por uma formação que revela uma tendência ao ecletismo teórico e dificuldades na apropriação dos avanços científicos mais recentes da área. O estudo aponta a necessidade de um maior investimento das instituições formadoras e dos profissionais atuantes, para ampliar o campo de atuação do psicólogo escolar e possibilitar práticas emancipatórias.
\end{abstract}

Palavras-chave: Psicologia Escolar, atuação do psicólogo, rede particular de ensino.

\section{The school psychologist's performance in the private teaching network}

\begin{abstract}
Recent studies relating to the performance of school psychologists have focused predominantly on public teaching. In this study we investigate school psychologists working in the private teaching system. We base our work on qualitative assumptions, within a historical-cultural perspective. For this, we carried out semi-structured interviews with twelve school psychologists of private schools from Uberlandia, in the state of Minas Gerais. Results show that the insertion of these psychologists in the private educational system reflects, among other factors, historical issues related to the constitution of School Psychology in Brazil, which, in its turn reveals the professional's social image. The works developed by these professionals are predominantly traditional, tending to a theoretical eclecticism, revealing difficulties in the appropriation of more recent contribution in the area. The study points to the need of a greater investment from Educational institutions as well as the necessity of school psychologists to broaden their field of performance.
\end{abstract}

Keywords: School psychology, psychologist performance, private teaching network.

\section{La actuación del psicólogo escolar en la red de enseñanza privada}

\section{Resumen}

Los trabajos encontrados en literatura reciente sobre la actuación del psicólogo escolar enfocan, predominantemente, el ámbito de la enseñanza pública. Por lo tanto, este estudio investiga la práctica de este profesional en la red de enseñanza privada, fundamentado en supuestos cualitativos, bajo la perspectiva histórico-cultural. Realizamos entrevistas semiestructuradas con doce psicólogos escolares de la red de enseñanza privada de la ciudad de Uberlândia/MG y constatamos que su inserción en el segmento educacional privado refleja, entre otros factores, cuestiones históricas relacionadas a la constitución de la Psicología Escolar en Brasil, desplegadas en la imagen social del psicólogo escolar. Las modalidades de trabajo desarrolladas por los participantes de este estudio son predominantemente tradicionales, sustentadas por una formación que revela una tendencia al eclecticismo teórico y dificultades en la apropiación de los avances científicos más recientes del área. El estudio indica la necesidad de mayor inversión de las instituciones formadoras y de los profesionales actuantes, para ampliar el campo de actuación del psicólogo escolar y posibilitar prácticas emancipadoras.

Palabras clave: Psicología Escolar, actuación del psicólogo, red enseñanza privada. 


\section{A atuação do psicólogo escolar}

\section{na rede particular de ensino}

Concordamos com Tanamachi e Meira (2003, p. 11) quando afirmam: "o que define um psicólogo escolar não é o seu local de trabalho, mas o seu compromisso teórico e prático com as questões da escola". No tocante ao ensino particular, o psicólogo encontra-se numa realidade diferenciada, cujas contradições sociais se revelam na própria origem da escola particular no Brasil, marcada por interesses político-ideológicos, nos quais se evidencia claramente a orientação liberal que privilegia as classes mais favorecidas, conforme afirma Buffa (1979). A autora esclarece que o desenvolvimento da escola particular teve como contexto histórico a consolidação do desenvolvimento industrial no país, que entendia a educação como um "processo de adaptação às relações capitalistas de produção, adaptação essa que assegura aos filhos da classe dominante as vantagens e privilégios de sua classe e adapta os filhos da classe dominada às condições de exploração a que são submetidos" (Buffa, 1979, p. 98). Sob este aspecto, para além da competência técnica, o psicólogo precisa investir-se de compromisso político e estar atento aos limites éticos de sua atuação, tendo em vista as várias concepções de educação, interesses e ideologias que atravessam os indivíduos e as instituições.

Para abrangermos os limites da inserção do trabalho do psicólogo escolar na rede particular de ensino, é preciso considerar que a escola particular possui algumas peculiaridades, tais como: clientela de classe média e alta, condições de trabalho diferenciadas, disponibilidade de recursos humanos e financeiros que proporcionam à sua administração autonomia e liberdade e, comparada à escola pública, melhor remuneração de professores e funcionários, melhor estrutura física e possibilidade de interferência de diretores e pais nas decisões da instituição (Benzi, 1996). Entretanto, tais características apresentam-se de maneira diversa nos vários contextos educacionais da rede particular, pois, mesmo dentro deste segmento, existem outros fatores que incidem sobre a sua constituição, como: diferenças de classe social, tipo de gestão escolar e condições histórico-culturais singulares.

Para Sant'anna (1984, citado por Castanho, 1990, p. 11), o segmento de ensino privado é caracterizado por forte pressão institucional, "porque as escolas se reservam o direito de exigir um tipo de trabalho específico, que nem sempre está de acordo com o modelo mais adequado, do ponto de vista psicológico". Sob este enfoque, no que se refere à inserção do psicólogo escolar, Benzi (1996) sugere que as maiores dificuldades enfrentadas pelo profissional são a falta de respaldo legal para a presença do psicólogo no sistema educacional e a falta de conhecimento do trabalho deste profissional, muitas vezes entendida como uma atuação clínica. Assim, fatores como condições de trabalho, visão dos demais profissionais da escola acerca da sua atuação, tipos de práticas realizadas, dentre outros, configuram-se questões importantes para se compreender o seu lugar na rede particular de ensino como campo de atuação. Percebe-se que grande parte das pesquisas sobre a atuação do psicólogo escolar é desenvolvida no âmbito do ensino público (Antunes e cols., 2003; Araújo \& Almeida, 2003; Galdini \& Aguiar, 2003; Neves \& Almeida, 2003; Machado, 2003; Souza, 2007; Saraiva 2007; dentre outros) e pouquíssimos trabalhos contemplam as especificidades do ensino particular (Benzi, 1996; Campos \& Jucá, 2003; Castanho, 1990; Rossetti, Silva, Batista, Stein, \& Hulle, 2004). Tais apontamentos indicam a necessidade de se conhecer e investigar de forma sistematizada os meandros que caracterizam o campo majoritário de trabalho do psicólogo no segmento particular de ensino como um fato, buscando um diálogo com a sua formação profissional. Assim, este estudo investiga a atuação do psicólogo escolar na rede particular de ensino, ampliando as possibilidades de discussão e aprimoramento da práxis neste contexto educacional específico.

\section{Método}

O presente trabalho fundamenta-se em pressupostos qualitativos, que consideram "as exigências epistemológicas inerentes ao estudo da subjetividade como parte constitutiva do indivíduo e das diferentes formas de organização social" (González-Rey, 2002, p. 28). Sob o referencial da Psicologia histórico-cultural, entende-se que toda e qualquer produção humana é desenvolvida na e pela cultura, ideologicamente inscrita dentro de um determinado contexto social (Vigotski, 2000). Nesta abordagem, escolhemos como recursos metodológicos a entrevista semiestruturada e o diário de bordo para a construção dos dados. Os participantes desta pesquisa são doze psicólogos escolares da rede particular de ensino da cidade de Uberlândia/MG. A escolha dos participantes foi realizada mediante o contato com os profissionais a partir de um primeiro levantamento realizado por telefone. Entramos em contato com aproximadamente noventa escolas particulares com o objetivo de identificar a presença de psicólogos atuantes neste segmento. A partir deste mapeamento, localizamos doze trabalhadores alocados em onze escolas. Conversamos com os profissionais pelo telefone, apresentando os objetivos da pesquisa e solicitando o agendamento para a realização de entrevistas semidirigidas. Estas foram gravadas em áudio para posterior transcrição.

Em nossos procedimentos de análise, abordamos três grandes eixos: modos de atuação, inserção e formação do psicólogo. Consideramo-los mais representativos das principais temáticas emergidas no contato com os participantes deste trabalho. Ao longo da pesquisa, atentamo-nos para o modo como os profissionais se inserem na instituição, considerando: a origem do serviço de Psicologia Escolar na mesma, a conquista do espaço, a imagem e o papel do psicólogo perante a comunidade escolar e a visão deste sobre os limites e as possibilidades do seu trabalho na rede privada de ensino, tendo em vista que a Psicologia históricocultural e sua correspondente perspectiva crítica preveem que a análise de qualquer fenômeno deve ser abrangente, considerando-se os múltiplos fatores que o constituem. 


\section{Resultados e discussões}

Observamos que a maioria dos profissionais participantes de nosso estudo é constituída por mulheres (83\%) com idade entre 25 e 35 anos. Em relação ao tempo de conclusão da graduação em Psicologia, $75 \%$ dos entrevistados possuem menos de 10 anos de formação, $42 \%$ têm de 5 a 10 anos e $33 \%$, até 5 anos. Tais dados indicam uma formação relativamente recente. Cinco psicólogos atuam na área escolar há menos de cinco anos (42\%), e cinco já possuem de cinco a dez anos de atuação (42\%). A maioria dos profissionais estudou em instituições federais de Ensino Superior, sendo que apenas dois entrevistados se formaram em instituições particulares.

Em relação aos cargos ocupados pelos participantes da pesquisa, $75 \%$ ocupam a posição de psicólogo, sendo que dois estão no cargo de orientador educacional e um no de coordenador educacional. A maioria dos psicólogos (75\%) exerce atividades no Ensino Fundamental e Médio e $42 \%$ dos profissionais atuam no Pré-vestibular. Apenas quatro entrevistados atuam na Educação Infantil, correspondendo a $33 \%$ do total de participantes.

Quanto ao público atendido, identificamos que todos os psicólogos realizam atividades com estudantes e pais e a maioria trabalha com professores (75\%). A atuação junto aos demais funcionários da escola é realizada por $58 \%$ dos profissionais entrevistados. Embora alguns psicólogos tenham optado por não revelar a sua remuneração, a média salarial daqueles que responderam é de aproximadamente 1500 reais mensais, distribuídos em aproximadamente 30 horas de trabalho semanal.

No que diz respeito a outros vínculos empregatícios, seis psicólogos atuam em outras áreas da Psicologia, concomitantemente à atuação em Psicologia Escolar, sendo que quatro deles trabalham como psicoterapeutas. Este dado indica que as condições de trabalho são muito específicas, de acordo com a realidade de cada instituição, e não caracterizam um padrão profissional da categoria. A remuneração e a quantidade de horas trabalhadas é variável, sendo que alguns psicólogos atuam em condições desvantajosas com relação aos demais profissionais.

Observamos que a inserção do psicólogo escolar na rede particular de ensino está relacionada a muitos aspectos envolvidos na entrada e permanência deste profissional na escola, tais como: a origem do serviço de psicologia nas escolas particulares, as expectativas e demandas criadas pelos gestores e demais profissionais sobre a atuação do psicólogo escolar. A maioria dos entrevistados identificou expectativas e demandas da comunidade escolar para a realização de atendimento clínico e individualizado, visão relacionada ao início da Psicologia Escolar no país (Silva, 2005), como ilustra a seguinte fala de uma das psicólogas:

Nós, muitas vezes, somos vistos dentro da escola como psicólogos clínicos, nós temos que tratar as pessoas. E eu vejo esse preconceito com relação à profissão do psicólogo clínico, são as principais barreiras para a gente vencer aqui.
Quanto ao surgimento do serviço de Psicologia Escolar na rede particular de ensino, ressaltamos a orientação profissional como uma atividade que tem estimulado a abertura de mercado de trabalho para o psicólogo, destacada por vários profissionais participantes do presente estudo. Diante dos relatos dos entrevistados, percebemos que a inserção do psicólogo escolar e a conquista de sua autonomia no trabalho, especialmente na rede particular de ensino, são caracterizadas por elementos que envolvem tanto questões históricas sobre o papel e a imagem do psicólogo na sociedade, o fato de a profissão de psicólogo escolar ser relativamente recente, em comparação com outras profissões ligadas à Psicologia e à Educação, quanto as condições específicas do contexto particular de ensino, ou seja, os limites e as possibilidades que a instituição privada apresenta para que o profissional desenvolva a sua prática. Observamos que o grau de autonomia do profissional para a realização dos seus projetos varia conforme estas condições históricoculturais e também de acordo com a trajetória pessoal e profissional de cada um. Alguns psicólogos afirmam estar a caminho da conquista de um espaço para o serviço de Psicologia Escolar, conforme assinala uma das entrevistadas:

Estamos tentando ainda, que não é uma inserção fácil de organizar, o psicólogo escolar, é uma instituição que valoriza, mas que está na busca de qual é o papel que, às vezes, se confunde um pouco com a pessoa.

Enquanto uns alegam ter condições e liberdade para criar e desenvolver atividades, outros se consideram tolhidos por uma estrutura fechada, resistente a mudanças, e sentem-se impossibilitados de uma atuação condizente com as funções do psicólogo escolar:

A gente, psicóloga da escola, acaba fazendo algumas coisas que não são muito da sua alçada. Então, se falta um professor, às vezes você tem que entrar na sala de aula e fazer um trabalho improvisado.

Tais constatações denotam sérios problemas relacionados à imagem deste profissional na instituição, advertindo para a necessidade de responsabilidade e empenho na consolidação de práticas que o identifiquem como um profissional capaz de colaborar efetivamente no processo educacional.

De acordo com a pesquisa de Rossetti e cols. (2004), na rede particular de ensino, a maioria dos profissionais considera desnecessária a presença do psicólogo na escola, e acreditamos que tal fato esteja relacionado ao desconhecimento sobre o verdadeiro alcance de sua atuação. Como é possível perceber nas falas de alguns participantes de nosso estudo, os maiores empecilhos na prática estão ligados às expectativas e à imagem que a comunidade escolar apresenta acerca do psicólogo, ora lhe atribuindo poderes acima dos de sua competência, ora desvalorizando suas funções, acreditando ser um trabalho supérfluo, ou simplesmente ignorando-as, como percebemos nas falas seguintes: 
Eu sou pau pra toda obra;

Em uma escola particular, se você não ajudar [nas questões administrativas, como matrícula], fica aquela questão de que o psicólogo não pode ajudar a gente (...) é difícil, às vezes vem uma demanda que você acaba atendendo.

Observamos que o ideário construído pela comunidade escolar acerca da função do psicólogo ainda é instável e confuso. Algumas pessoas desconhecem a função do psicólogo escolar, enquanto outras consideram este profissional uma figura supérflua na escola, ou até mesmo um trabaIhador capaz de resolver todos os problemas que surgem na instituição, conforme também apontam as pesquisas de Castanho (1990) e Rossetti e cols. (2004).

Diante disto, ainda que os avanços mais recentes na área de Psicologia Escolar direcionem-se para uma mudança nos modelos de atuação, na adoção de posturas menos individualizantes que caracterizem uma abordagem clínica tradicional e buscando-se criar novas posturas e práticas, como as que se direcionam para trabalhos de natureza coletiva, que envolvam professores como parceiros e que contextualizem os problemas educacionais, as marcas históricas permanecem e incidem sobre a imagem do psicólogo escolar. Ademais, alguns psicólogos ainda trabalham numa perspectiva tradicional, revelando desconhecimento sobre o movimento histórico de abandono de práticas individualizantes que a Psicologia Escolar tem realizado, e acabam contribuindo para que a imagem do psicólogo tradicional prevaleça.

Por meio do relato da trajetória de alguns dos profissionais entrevistados, notamos que, embora a Psicologia tenha conquistado espaço na escola, a inserção dos psicólogos escolares foi predominantemente gerada a partir da Psicologia Clínica, não havendo uma proposta específica de atuação em Psicologia Escolar, conforme ilustra o seguinte relato:

A gente foi construindo essas demandas, qual era o objetivo de um psicólogo aqui e, no início, assim que eu me lembro, eu atuava muito com anamnese dos alunos. Hoje já não existe mais assim, não é de real necessidade, só quando precisa.

Desse modo, entendemos ser esta uma das razões pelas quais o psicólogo escolar tem encontrado tantas expectativas institucionais para o atendimento clínico e individual e como a mudança no modelo de atuação representa um desafio a ser superado, de forma a refletir na construção de uma imagem social da profissão, fundamentada em práticas diferenciadas.

Ao serem questionados sobre os limites e as possibilidades de atuação do psicólogo escolar na rede particular de ensino, os psicólogos manifestaram opiniões diferenciadas e até mesmo opostas entre si no que diz respeito às especificidades da escola particular. Assim, um grupo de profissionais apresenta concepções mais otimistas, ressaltando as inúmeras possibilidades de realização de projetos, enquanto outros realçam os desafios com que se deparam na prática. Observamos na fala de alguns que, conforme Benzi (1996) assinalou, a disponibilidade de recursos humanos e financeiros que propiciam autonomia à administração da escola é uma das particularidades da instituição privada e tal condição pode ampliar ou restringir a possibilidade de realização de determinados projetos pelo psicólogo escolar.

No tocante às relações entre escola e mercado, enquanto alguns psicólogos conseguem entrever a lógica mercadológica que constitui a escola particular, outros, em nenhum momento, apontam para esta questão. Contudo, percebemos que, mesmo consciente desta relação, o profissional muitas vezes torna-se "refém" desse sistema, o que interfere na sua motivação para o trabalho. Neste âmbito, uma das psicólogas mencionou que as suas condições de serviço estão muito relacionadas à sua capacidade de atender a uma demanda que visa à produção de notas e, ao mesmo tempo, precisa agradar aos alunos, situação que the causa pressão:

Às vezes eu vejo que na escola particular tem essa questão do produto: a nota - tem que passar de ano e no vestibular. Então esses são os limites.

Outro desafio relaciona-se ao delineamento de suas funções na instituição, que está relacionado ao fato de ele ter que desenvolver os seus projetos de modo pioneiro ou mesmo relacionado a outros psicólogos escolares que tenham passado pela instituição e implantado um serviço de psicologia escolar:

No dia em que eu vim conversar com a diretora da escola, as experiências que ela tinha tido anteriormente com psicólogos não tinham sido muito positivas, porque eles vinham para dentro da escola para clinicar.

Neste sentido, verificamos que o fato de já terem passado outros profissionais na instituição não significa que isso promova ou facilite a atuação do psicólogo, pois as experiências relatadas pelos participantes da pesquisa indicam que nem sempre a história do serviço de psicologia logrou êxito, uma vez que alguns profissionais que se denominavam "psicólogos escolares" passaram pela instituição e atuaram como psicólogos clínicos, numa abordagem individualizante e remediativa, imprimindo marcas na comunidade escolar que, consequentemente, não contribuíram para a construção da imagem social do psicólogo escolar tal qual é apreendida atualmente.

Desta maneira, compreendemos que os desafios não se limitam às expectativas quanto ao papel do psicólogo escolar. É preciso convir que, junto a essas perspectivas, existem determinadas demandas que, vindas da parte dos gestores escolares, apresentam-se diante do psicólogo como atividades imediatas a serem cumpridas. Sobre isso, Sant'anna (1984, citado por Castanho, 1990) aponta que, no segmento particular de ensino, as escolas se reservam o direito de exigir um tipo de trabalho específico que nem sempre se coaduna aos objetivos do psicólogo. Um exemplo 
desta realidade é a substituição de professores, citada por dois profissionais participantes de nosso estudo.

A visão que os profissionais demonstram a respeito das condições de trabalho na instituição particular parece estar relacionada à abertura que os dirigentes da escola oferecem para a criação de novas frentes de trabalho, ao papel atribuído ao psicólogo neste espaço e até mesmo à percepção do próprio psicólogo acerca dos seus objetivos profissionais e de como ele entende as relações empregatícias no contexto institucional e social. Por outro lado, fatores mais ligados à trajetória profissional, sua busca por coerência e sustentação teórica para a prática, por meio de constante atualização profissional, também conferem determinadas posturas que contribuem para sua inserção e permanência na escola. Percebemos que alguns profissionais apresentam maior disposição pessoal para dar continuidade à sua formação e aprimoramento. Sob este enfoque, Martínez (2003) afirma ser importante que o psicólogo escolar desenvolva competências específicas e características pessoais para legitimar o seu espaço na instituição. A autora destaca, dentre as características e competências necessárias, as habilidades de comunicação, capacidade de trabalhar em equipe, criatividade, autocrítica e comprometimento com os resultados do trabalho. Tais aspectos estão relacionados à formação pessoal que, segundo a autora, tem sido negligenciada nos cursos de graduação em Psicologia.

No que se refere aos modos de atuação do psicólogo escolar, identificamos objetivos e estratégias diferenciadas na atuação de cada profissional. Algumas atividades foram mencionadas pela maioria dos profissionais, dentre as quais destacamos a intervenção junto aos professores, a orientação profissional, a intervenção em sala de aula, a intervenção junto aos pais e o atendimento aos alunos. Outras formas de atuação foram citadas apenas por um ou outro psicólogo: participação na gestão escolar, avaliação psicológica, análise e acompanhamento do desempenho escolar, atendimento aos alunos, orientação disciplinar, elaboração, organização e execução de eventos, orientação de estudos, reunião mensal com alunos representantes de sala, levantamento de dados sobre perfil de alunos, assessoria, recrutamento, seleção e treinamento de funcionários.

Souza (2009) afirma que as novas perspectivas em Psicologia Escolar e Educacional referem-se, dentre outras questões, à ampliação das áreas tradicionais de atuação do psicólogo. Neste sentido, Martínez (2009) salienta que tanto as práticas tradicionais como as consideradas emergentes, se realizadas com criatividade e qualidade, podem propiciar impactos reais na melhoria dos processos educativos da escola. Valendo-nos da caracterização das práticas do psicólogo escolar, estabelecida por Martínez (2009), e mediante os relatos dos profissionais integrantes de nosso estudo, identificamos a existência de práticas tradicionais e emergentes. A maioria dos psicólogos adota práticas tradicionais como: a avaliação psicológica, o atendimento ao aluno e a orientação profissional. Entretanto, para além dessa classificação dicotômica tradicional versus emergente, é preciso considerar o caráter dialético das mudanças de perspectiva em Psicologia, analisando-se toda a história da Psicologia Escolar, bem como o contexto em que as práticas são desenvolvidas. Compreendemos que, mesmo realizando atividades consideradas tradicionais, o psicólogo pode ampliar o alcance de sua atuação, desde que esteja fundamentado em concepções que considerem a dimensão histórico-cultural da constituição humana. Neste sentido, Martínez (2009) destaca que a orientação profissional, considerada uma prática tradicional, tem passado por mudanças: de um trabalho baseado em testes para identificar interesses e habilidades dos alunos e analisar as melhores opções de cursos em função dos resultados obtidos, para espaços promotores de reflexão, autoconhecimento e elaboração de planos e projetos profissionais. Assim, há uma ampliação desta atividade, não se reduzindo ao momento de escolha profissional, mas abrangendo também o desenvolvimento de recursos psicológicos como criatividade, capacidade reflexiva e tomada de decisões, importantes não só para a escolha da profissão como também para a inserção do jovem no mundo do trabalho, o que pudemos constatar nos relatos dos participantes do estudo. Contudo, no que diz respeito à avaliação psicológica, ainda observamos a existência de concepções remediativas e individualizantes, contrariando a afirmação de Martínez (2009) segundo a qual "o caráter qualitativo, processual, comunicativo e construtivo do diagnóstico e da avaliação das dificuldades escolares vai superando, não sem dificuldade, o diagnóstico rotulador e estático que caracterizou o diagnóstico das dificuldades escolares durante muitos anos" (p. 170).

No que tange às intervenções em sala de aula, pudemos constatar que alguns profissionais tomaram a iniciativa de sistematizar algumas atividades em forma de disciplina na grade curricular, o que corresponde àquilo que Martínez (2009) considera como prática emergente. Nesta vertente, alguns psicólogos apresentaram outras práticas assim consideradas, como: participação na elaboração de propostas pedagógicas para as escolas, oficinas direcionadas ao desenvolvimento integral dos alunos, levantamento do perfil social dos alunos e participação no processo de seleção dos membros da equipe pedagógica. A prática de supervisão de estágio, embora não tenha sido citada pela autora, parece investir-se de caráter inovador, pois intenta ampliar as possibilidades de se agregar elementos teórico-práticos e articular atuação e formação do psicólogo nos contextos educacionais.

Quanto à formação profissional do psicólogo escolar, várias autoras têm se preocupado em investigar e discutir a formação dos psicólogos escolares (Cruces, 2003; Novaes, 2003; Patto, 2003; Silva, 2005; Souza, 2000; Tanamachi, 2000). Em nosso estudo, falas como não foi a minha primeira escolha; foi uma coisa de mercado de trabalho que me levou a isso [referindo-se à atuação como psicóloga escolar]; não é minha área de paixão; eu não via a Psicologia Escolar como um fim, não era meu foco [na graduação em Psicologia]; dentre outras, indicam que o encontro dos profissionais com a Psicologia Escolar, quase sempre, foi precedido por um grande desencontro, caracterizado por um 
desinteresse na formação inicial por este campo de atuação e pela consequente busca em encontrar subsídios teóricos e procedimentais para lidar com a realidade escolar. $\mathrm{Na}$ maioria das vezes, o psicólogo encontra uma oportunidade de emprego na área e somente a partir daí é que passa a se envolver mais com as questões educacionais. Neste sentido, Cruces (2003) ressalta que há uma grande predominância pela área clínica nas preferências dos psicólogos em formação. A autora assegura que isso ocorre porque, na história da Psicologia, o currículo privilegiou a área clínica em detrimento das demais, dando ênfase aos aspectos individuais do ser humano e, deste modo, a Psicologia Escolar sempre foi uma área pouco escolhidas tanto por estagiários quanto pelos psicólogos em serviço.

Em relação à fundamentação teórica dos profissionais, observamos a predominância de uma combinação de várias teorias psicológicas diferentes e até mesmo contraditórias em suas bases epistemológicas. Identificamos a ausência de um corpo específico de conhecimentos em Psicologia Escolar a nortear a atuação destes profissionais, sendo que alguns deles utilizam-se, predominantemente, de referenciais específicos com os quais têm maior afinidade. Existem profissionais que não atuam somente na área escolar, o que parece influenciar diretamente nas escolhas das abordagens teóricas que subsidiam suas práticas, uma vez que, frequentemente, os referenciais teóricos utilizados por aqueles que atuam também em outras áreas são transpostos para a esfera educacional ou servem para a leitura dos fenômenos vividos na escola. O mesmo acontece com a ênfase em alguns teóricos que foram mais estudados durante a graduação e que são utilizados para sustentar a atuação do psicólogo escolar. Pudemos identificar, no discurso de muitos profissionais, uma tendência à utilização "de tudo um pouco" (em relação às abordagens teóricas) na sua atuação, como se isso representasse uma garantia de se abranger as multideterminações dos fenômenos educacionais, como na seguinte fala: eu gosto de muitos teóricos e eu acabo aproveitando um pouco de cada área.

Sobre a preparação para o desenvolvimento de suas práticas, um dos entrevistados relata que "não há receita de bolo", fazendo referência à sua atuação no cotidiano da escola. No contexto da fala, percebemos que este expressou a sua angústia em estar continuamente exposto a demandas com as quais não tem familiaridade, sentindo-se despreparado para enfrentá-las. Analisando este e outros relatos, compreendemos que o âmbito escolar é desafiador para o psicólogo, justamente porque não se caracteriza como um trabalho rotineiro, exigindo do profissional dinamismo e flexibilidade para lidar com as mais diversas demandas que se apresentam. Contudo, para além dessa reflexão acerca da complexidade do contexto escolar, cabe-nos também ponderar acerca do (des)preparo dos profissionais diante dele. Sob este enfoque, a maioria dos entrevistados menciona a insuficiência da formação inicial para o trabalho nos contextos educacionais. Identificamos, na fala destes, uma crítica contundente à sua formação inicial, que deixou lacunas cujo efeito foi percebido na experiência profissional, devido à fal- ta de direcionamentos práticos. Daí a necessidade da busca de uma formação continuada para superar os desafios cotidianos. Neste sentido, um dos entrevistados admite:

Eu acredito que boa parte da minha prática escolar não foi obtida na faculdade (...), na universidade eu não tive muito respaldo, não.

Além disso, ele percebe que a formação em Psicologia Escolar não é satisfatória e é até desvalorizada na universidade, o que é corroborado por Almeida (2001, citada por Cruces, 2003).

Tendo em vista que nem sempre a formação inicial contempla um aprofundamento sobre os diferentes contextos educacionais e seus reflexos no exercício da atuação, compreendemos que o psicólogo escolar da rede particular de ensino se depara com um campo com o qual não teve familiaridade, isto é, ele não teve contato na graduação com discussões sistematizadas com base numa literatura específica acerca do ensino privado como contexto no qual poderia atuar. Desse modo, além de apresentar algumas dificuldades técnicas para desenvolver o seu trabalho, o profissional não detém uma bagagem teórica capaz de orientá-lo em questões específicas, como, por exemplo: as relações de poder existentes nas gestões privadas, a mercantilização da educação e o psicólogo como figura de "marketing", dentre outras questões que precisam ser problematizadas. Cruces (2003) entende que, na formação do psicólogo, é necessário refletir sobre as demandas de mercado que são direcionadas a este profissional. A autora recomenda que os centros de formação superior devem identificar, discutir e integrar aspectos relacionados à lógica mercadológica na formação dos psicólogos. Nesse sentido, Souza (2000, p.136) afirma que uma das perguntas que se deve fazer em relação à formação profissional é justamente esta: "que compromisso deve ter o profissional psicólogo que queremos formar?”. A relação mercadológica prevalece explicitamente em grande parte das instituições escolares privadas, nas quais o aluno é um cliente que, juntamente com os pais, exige receber, em troca do capital investido, uma "educação de qualidade". Tal conjuntura influencia na atuação do psicólogo, conforme percebemos no seguinte relato:

A cultura organizacional é a escola de resultado: aluno que tem resultado fica, os que não, vão embora, são rechaçados, excluídos. A cultura da competência exclui os incompetentes.

Desse modo, percebe-se mais claramente a noção de "capital humano", herança da concepção burguesa, na qual se estreitam os vínculos entre a prática educativa escolar e o modo de produção capitalista (Frigotto, 1984).

Como vimos, são inúmeras as questões envolvidas na prática do psicólogo escolar e, diante delas, torna-se urgente também compreender a relação entre a formação deste profissional e os desafios inerentes à profissão. Nessa perspectiva, Campos e Jucá (2003, p. 43) discutem a atua- 
ção deste profissional frente às demandas do mercado, relacionando a formação do mesmo com as mudanças e imposições do trabalho. Percebem uma necessidade de se refletir acerca das demandas do mercado de trabalho direcionadas aos psicólogos escolares, ao se avaliar a formação. Os autores questionam: "é indicado concluir que as atividades desenvolvidas pelos psicólogos estão acordes com o que é demandado dele? E a formação acadêmica tem habilitado os profissionais para atuar na perspectiva do novo ou do tradicional?". Neste sentido, compreendendo esta formação como fundamental para um bom exercício profissional. No que diz respeito à atuação do psicólogo na rede particular de ensino, Benzi (1996) aponta como um problema ético da Psicologia Escolar o fato do ensino e a pesquisa da área se voltarem mais para a clientela da rede pública do que para a da rede privada e considera que se negligencia uma camada social que também apresenta dificuldades ao deixar de enfocar e pesquisar sua especificidade.

\section{Considerações finais}

A construção deste estudo nos conduziu a três eixos de análise que se articulam: a inserção do psicólogo na rede particular de ensino, as suas práticas e a formação profissional. Percebemos que não há como compreender a prática do psicólogo escolar sem analisar o caminho por ele percorrido, tanto em sua formação inicial e continuada quanto em seu ingresso e permanência na instituição privada. Debruçandonos sobre os relatos dos participantes do presente estudo, encontramos registros de uma profissão ainda em consolidação, que apresenta um vasto campo a ser desenvolvido e que carece de maior investimento por parte das instituições formadoras e dos profissionais atuantes. Constatamos que a inserção do psicólogo escolar e a conquista de sua autonomia na rede particular de ensino são perpassadas por questões históricas relacionadas à constituição da Psicologia Escolar no Brasil e seus desdobramentos na imagem social do psicólogo escolar, bem como pelas condições específicas do contexto particular de ensino, envolvendo limites e possibilidades que a instituição privada apresenta ao profissional. O contexto no qual o psicólogo atua é constituído por vários fatores que devem ser levados em consideração no momento da elaboração e realização de atividades. Neste sentido, compreendemos que uma instituição privada é uma empresa que abriga a educação como mercadoria principal e, sendo assim, os efeitos deste pressuposto no cotidiano escolar devem ser identificados e analisados pelo profissional atuante, bem como confrontados com a dimensão ética que rege a sua atuação. Muitos psicólogos percebem as nuances que a lógica mercadológica lança sobre o seu trabalho, realçando os desafios com que se deparam na prática, por meio de interferências, como algumas restrições no desenvolvimento de projetos que precisam de custeio maior por parte da escola e a preocupação excessiva em torno dos resultados, das notas dos alunos. Por outro lado, outros profissionais destacam as várias possibilidades de realiza- ção de projetos com autonomia e flexibilidade e a própria disponibilidade de recursos financeiros que a escola particular propicia. Verificamos que as mudanças nas práticas do psicólogo podem se concretizar de maneira gradual e dentro do próprio espaço tradicionalmente conquistado, tendo em vista que o diferencial não está encerrado na prática em si, da forma como ela é denominada, mas sim no modo como é conduzida e nos objetivos do profissional que a realiza. Assim, na orientação profissional, nos atendimentos a alunos e pais e nas demais frentes de atuação, o psicólogo pode encontrar brechas para trabalhar - não priorizando a lógica do mercado que massifica e pede por resultados - e sim acompanhando o processo no qual o indivíduo constitui a sua singularidade e o desenvolvimento humano de alunos, pais e equipe pedagógica.

Ademais, acreditamos que os psicólogos escolares estão num momento histórico importante para a consolidação da sua identidade profissional e, portanto, suas práticas merecem toda a atenção, não só da comunidade acadêmica, que forma novos profissionais, como também dos próprios psicólogos que têm a responsabilidade pela construção coletiva de sua profissão perante a sociedade. Desse modo, consideramos fundamental o investimento em formação continuada, para que eles "tenham oportunidades de refletir sobre as questões emergentes de sua prática à luz dos avanços teórico-críticos já conquistados" (Meira, 2000, p. 67). Assim, consideramos que as discussões referentes à atuação do psicólogo escolar na rede particular de ensino não se esgotam neste trabalho, sendo importante que a este se somem novos estudos e pesquisas, visando à construção de práticas cada vez mais emancipatórias.

\section{Referências}

Antunes, M. A. M. e cols. (2003). A Psicologia Escolar na implementação do Projeto Político-Pedagógico da Rede Municipal de Ensino de Guarulhos: construindo um trabalho coletivo. Em M. E. M. Meira \& M. A. M.Antunes, (Orgs.), Psicologia Escolar: Práticas críticas (pp. 105-128). São Paulo: Casa do Psicólogo.

Araújo, C. M. M., \& Almeida, S. F. C. (2003). Psicologia Escolar institucional: desenvolvendo competências para uma atuação relacional. Em S. F. C. Almeida (Org.), Psicologia Escolar: ética e competências na atuação e formação profissional (pp. 59-82). Campinas, SP: Alínea.

Benzi, N. P. (1996). Psicologia escolar na rede particular de ensino de Campinas. Dissertação de Mestrado, Pontifícia Universidade Católica de Campinas, Campinas, São Paulo.

Buffa, E. (1979). Ideologias em conflito: escola pública e escola privada. São Paulo: Cortez \& Moraes.

Campos, H. R., \& Jucá, M. R. B. L. (2003). O psicólogo na escola: avaliação da formação à luz das demandas do mercado. Em S. F. C. de Almeida (Org.), Psicologia escolar. ética e competências 
na formação e atuação profissional (pp. 37-56). Campinas, SP: Alínea.

Castanho, M. I. S. (1990). Possibilidades e limites de um trabalho em Psicologia Escolar: relato de experiência. Dissertação de Mestrado, Universidade de São Paulo, São Paulo.

Cruces (2003). Psicologia e educação: nossa história e nossa realidade. Em Em S. F. C. de Almeida (Org.), Psicologia Escolar: ética e competências na atuação e formação profissional (pp. 1736). Campinas, SP: Alínea.

Frigotto, G. (1984). A produtividade da escola improdutiva: um (re) exame das relações econômico-social e capitalista. São Paulo: Cortez.

Galdini, V., \& Aguiar, W. M. J. (2003). Intervenção junto a professores da rede pública: potencializando a produção de novos sentidos. Em M. E. M. Meira \& M. A. M. Antunes (Orgs.), Psicologia Escolar: práticas críticas (pp. 87-103). São Paulo: Casa do Psicólogo.

González-Rey, L. F. (2002). Pesquisa qualitativa em Psicologia caminhos e desafios. São Paulo: Thompson Learning.

Machado, A. M. (2003). Os psicólogos trabalhando com a escola: intervenção a serviço do quê?. Em M. E. M. Meira \& M. A. M. Antunes (Orgs.), Psicologia Escolar: práticas críticas (pp. 63-85). São Paulo: Casa do Psicólogo.

Martínez, A. M. (2003). O psicólogo na construção da proposta pedagógica da escola: áreas de atuação e desafios para a formação. Em S. F. C. de Almeida (Org.), Psicologia escolar: ética e competências na formação e atuação profissional (pp.105-124). Campinas, SP: Alínea.

Martínez, A. M. (2009). Psicologia Escolar e Educacional: compromisso com a educação brasileira. Revista Semestral da Associação Brasileira de Psicologia Escolar e Educacional (ABRAPEE), 13(1), 169-178.

Meira, M. E. M. (2000). Psicologia Escolar: pensamento crítico e práticas profissionais. Em E. R. Tanamachi, M. Proença \& M. Rocha (Orgs.), Psicologia e Educação: desafios teórico-práticos (pp. 35-71). São Paulo: Casa do Psicólogo.

Neves, M. M. B. da J., \& Almeida, S. F. C. (2003). A atuação da psicologia escolar no atendimento aos alunos encaminhados com queixas escolares. Em S. F. C. de Almeida (Org.), Psicologia escolar. ética e competências na formação e atuação profissional (pp. 83-103). Campinas, SP: Alínea.
Novaes, M. H. (2003). Repensando a formação e o exercício profissional do psicólogo escolar na sociedade pós-moderna Em S. F. C. de Almeida (Org.), Psicologia escolar. ética e competências na formação e atuação profissional (pp. 127 a 134). Campinas, SP: Alínea.

Patto, M. H. S. (2003). O que a história pode dizer sobre a profissão do psicólogo: a relação Psicologia-Educação. Em A. M. B. Bock (Org.), Psicologia e o compromisso social (pp. 29-35). São Paulo: Cortez.

Rossetti, C. B., Silva, C. A., Batista, G. L., Stein, L. A., \& Hulle, L. de O. (2004). Panorama da Psicologia Escolar na cidade de Vitória: um estudo exploratório. Cadernos de Psicologia e Educação Paideia, 14(28), 191-195.

Saraiva (2007). Olhares em foco: tensionando silenciamentos. Em B. P. Souza (Org.), Orientação à queixa escolar (pp. 59-77). São Paulo: Casa do Psicólogo.

Silva, S. M. C. (2005). Psicologia Escolar e Arte - uma proposta para a formação e atuação profissional. Campinas, SP: Alínea/ EDUFU.

Souza, M. P. R. (2007). Prontuários revelando os bastidores do atendimento psicológico à queixa escolar. Em B. P. Souza (Org.), Orientação à queixa escolar (pp. 27-58). São Paulo: Casa do Psicólogo.

Souza, M. P. R. (2009). Psicologia Escolar e Educacional em busca de novas perspectivas. Revista Semestral da Associação Brasileira de Psicologia Escolar e Educacional (ABRAPEE), 13(1), 179-182.

Souza, M. P. R. (2000). A queixa escolar na formação de psicólogos: desafios e perspectivas. Em E. R. Tanamachi, M. Proença \& M. Rocha (Orgs.), Psicologia e Educação: desafios teórico-práticos (pp. 105-142). São Paulo: Casa do Psicólogo.

Tanamachi, E. R. (2000). Mediações teórico-práticas de uma visão crítica em Psicologia Escolar. Em E. R. Tanamachi, M. Proença \& M. Rocha (Orgs.), Psicologia e Educação: desafios teóricopráticos (pp. 73-104). São Paulo: Casa do Psicólogo.

Tanamachi, E. R., \& Meira, M. E. M. (2003). A atuação do psicólogo como expressão do pensamento crítico em Psicologia e Educação. Em M. E. M. Meira \& M. A. M. Antunes (Orgs.), Psicologia Escolar: práticas críticas (pp. 11-62). São Paulo: Casa do Psicólogo.

Vigotski, L. S. (2000). Manuscrito de 1929. Educação e Sociedade, 21(71), 21-44. 
Recebido em: 25/3/2010

Reformulado em: 15/10/2010

Aprovado em: 2/2/2011

\section{Sobre os autores}

Cláudia Silva de Souza (claudia2008udia@hotmail.com)

Universidade Federal de Uberlândia

Maria José Ribeiro

Universidade Federal de Uberlândia

Silvia Maria Cintra da Silva

Universidade Federal de Uberlândia

Endereço para correspondência:

Av. Portugal-796- Tibery- Uberlândia-MG CEP; 38405-042

Este trabalho é resultado da dissertação de mestrado de Cláudia Silva de Souza, sob a orientação das professoras Dra. Silvia Maria Cintra da Silva e Dra. Maria José Ribeiro. Para a sua realização, contamos com o apoio financeiro da CAPES. 